\title{
Derecho de ciudadanos y para ciudadanos*
}

\author{
GUILLERMO HOYOS VÁSQUEZ**
}

En una de las primeras reacciones ${ }^{1}$ a la traducción española de la Filosofía del derecho de jürgen Habermas, Facticidad y validez. Sobre el derecho y el Estado democrático de derecho en términos de teoría del discurso ${ }^{2}$, afirma Manuel Reyes Mate que con esta obra el autor "saca del infierno al Derecho". En efecto, hasta ahora el derecho parecía ser el privilegio de unos cuantos, de los poderosos, el arma coactiva al servicio del dinero y del poder, en cierto sentido como legitimación del sistema dominante.

La desconfianza del ciudadano común y corriente frente al derecho también es comprensible, si se tienen además en cuenta ciertos aspectos muy relacionados con la especialización de los discursos jurídicos. Frente a esta situación real del derecho, la pregunta que orienta estas reflexiones es si es posible volver a acercar el derecho a lo que en la tradición republicana moderna se conoce como la 'soberanía popular', es decir, si es posible e inclusive necesario que el derecho sea reconocido por los ciudadanos como su instrumento para la solu- ción de conflictos y para la organización de la cooperación en procura del bien común. Es decir, si el derecho puede dejar de ser instrumento de dominación para convertirse en estrategia de emancipación.

En concreto en los procesos de paz el derecho debería cumplir una función insustituible. Los compromisos a los que se pueda llegar tienen carácter de contratos, acuerdos y formas de derecho. El reconocimiento en el tiempo de dichos pactos es garantía para pensar en la estabilidad de lo acordado. Se requiere pues cierta comprensión del sentido mismo de las formas jurídicas, como instrumentos que permiten formular consensos y conservarlos en el tiempo, de forma que su cumplimiento pueda ser exigido, si fuere necesario, inclusive coactivamente. Esta comprensión del derecho exige de las partes que llegan a dichos acuerdos un mínimo de compromiso y autenticidad, gracias a los cuales los contratantes puedan confiar mutuamente en el valor de la palabra y en su cumplimiento.

\footnotetext{
Conferencia pronunciada en el espacio académico de la Cátedra Libre Fray Bartolomé de Las Casas en octubre de 2004.

** Departamento de Filosofía, Universidad Nacional de Colombia, Bogotá.

1 En El País de Madrid, primera semana de abril de 1998.

2 Madrid: Trotta, 1998.
} 
La tesis habermasiana que trataremos de hacer comprensible en este trabajo es la siguiente: el derecho como producción social y cultural tiene que poder ser reconstruido a partir de su origen en la actividad política, para darle legitimidad y validez. Sin perder su sentido positivo, su forma jurídica, el derecho es 'instrumento'; expuesto por tanto a los riesgos de la racionalidad estratégica, puede ser manipulado por el poder o el capital para colonizar desde determinados intereses el mundo de la vida de la sociedad civil. Pero como instrumento también puede ser 'correa de transmisión' de los intereses de la solidaridad, ese tercer recurso de socialización, para humanizar los otros dos recursos de socialización en los ámbitos del dinero y el poder político. Quiere decir que si el derecho ha sido utilizado como instrumento de dominación, también puede ser instrumento de liberación, no sólo como lo concibió el primer liberalismo, en cuanto posibilita la superación del estado de naturaleza, sino en el sentido del republicanismo, como emancipación política.

Precisamente por esta función ambigua del derecho moderno, cobra cada vez más importancia en la discusión contemporánea, en los discursos de la filosofía moral y política, clarificar el sentido del derecho en relación tanto con la moral como con la política. El derecho postmetafísico y secularizado tiene cada vez menos recursos de legitimación en metarrelatos religiosos o morales y recurre cada vez más a autolegitimarse en su propia racionalidad o en su funcionalidad. La teoría de la acción comunicativa, articulada con sentido como "ética para ciudadanos" ${ }^{\prime 3}$, puede ayudar ahora como teoría discursiva del derecho para reconstruir los tejidos políticos que permitan a los ciudadanos como autores del derecho reapropiarse de sus funciones.

En efecto, si se piensa que no toda acción instrumental va en contra de los intereses de la persona y la comunidad, es decir, si se acepta que no sólo la acción comunicativa despliega en el mundo de la vida de la sociedad civil los intereses auténticos de las personas, sino que también lo que de ella resulte, como pueden ser precisamente los acuerdos, es posible comprender que el derecho, como producto de tales procedimientos, gana su legitimidad a partir de ellos sin perder su forma jurídica específica, pero tampoco sin que se reduzca todo su sentido a mera legalidad. La tesis del positivismo jurídico ha sido que la validez legal legitima el derecho y que por ello no es necesario deducirlo de la moral, como lo demostrara Kant. Para una teoría discursiva del derecho, como la desarrolla Habermas, el derecho sí es independiente de la moral, pero su legitimidad se funda en los procesos que lo producen. Así recobra el derecho su estrecha relación con la política, dado que su fuente ya no es la moral sino el principio deliberativo de la democracia, con lo cual también la política adquiere su sentido positivo en relación con la convivencia social.

Con esto queda claro el propósito de mis reflexiones. Para que el derecho vuelva a ser de los ciudadanos en cuanto ciudadanos, su legitimidad ha de venir dada por un sentido fuerte de democracia, como campo de ejercicio libre de los intereses y derechos de los miembros de la sociedad. En la Constitución Colombiana se llama a esta forma de participación en la 'polis' "democracia participativa". En lo que sigue busco mostrar las íntimas relaciones entre este sentido de democracia y un Estado de derecho que pretenda legitimidad y no sólo eficiencia. Con ello se habrá mostrado un camino para solucionar concertadamente aquellos conflictos que parecen oponerse a todos los propósitos de paz. Un derecho cuyo sentido radique en ser instrumento de la soberanía popular estará necesariamente al servicio de la paz y no de la guerra.

3 Ver mi “Ética para ciudadanos”. En: GIRALDO, Fabio y VIVIESCAS, Fernando (compiladores). Pensar la ciudad. Bogotá: Tercer Mundo, 1996, p. $287-310$. 


\section{La democracia como participación ${ }^{4}$}

La Asamblea Nacional Constituyente de Colombia, febrero a julio de 1991, convocada con base en un proceso de participación ciudadana, diseñada para dar cabida en la democracia inclusive a la guerrilla más antigua de Latinoamérica, proclama ya en el preámbulo de la nueva Constitución "un marco jurídico, democrático y participativo que garantice un orden político..." y ya desde el primer Artículo constituye paradigmáticamente la nación como República "democrática, participativa y pluralista". En su instalación expresaba el Presidente de los colombianos de manera programática que, dado que "la clave de la legitimidad es la participación", con la nueva Carta el país se proponía "construir una democracia participativa en la cual todos podamos participar en lo que a todos concierne. Que nadie sea excluido de los beneficios, responsabilidades y cargas de la vida comunitaria. Así la igualdad y la solidaridad, dos valores esenciales de la democracia participativa, podrán ser llevados a la práctica para que acompañen las banderas de la libertad" ${ }^{5}$. $Y$ al proclamarse la nueva Constitución, destacaba: "Ya no se habla de la democracia a secas, sino de una democracia de participación popular... Estamos frente a una nueva concepción de la democracia, quizás la más avanzada de que se tenga noticia... hoy los inspiradores de la democracia participativa han desafiado las instituciones tradicionales, no para destruirlas sino para tomarlas como pilares de un nuevo orden político más legítimo, más respetuoso de la autonomía, de los derechos y de la libertad de cada persona, menos desigual y más justo, abierto a la convivencia pacífica de todos los grupos que conforman una comunidad"6. 1996 terminó con la firma de la paz en Guatemala, después de un diálogo que puso fin a 39 años de lucha e instauró, según expresión de uno de los guerrilleros: "una democracia real y participativa". Como se buscó también hace poco con la firma de la paz en El Salvador. Lo que se reclama con "democracia participativa" no es tanto una nueva forma de democracia, sino precisamente la realización de la misma: la democratización de la democracia.

Las discusiones en torno al sentido de la democracia participativa destacan las siguientes características: es fuente última de legitimidad en cuanto es génesis democrática del Estado de derecho; conforma el espacio público pluralista necesario para el debate, el aprendizaje con base en razones y la concertación motivada; da sentido a una política de la solidaridad, la equidad y la paz, comprometiendo a cada uno de los ciudadanos con el destino común. Por ello se espera que la democracia participativa permita realizar efectivamente la justicia en un Estado social de derecho, con lo que se privaría de uno de sus argumentos a la violencia guerrillera; su otro argumento, el de la exclusión y persecución ideológica, se desmonta con la invitación a la participación y se refuta con los resultados que se logren con ella. Finalmente la democracia participativa sería el mejor correctivo de la corrupción, parásito de la política que la priva de toda legitimidad y ha llevado a los partidos tradicionales al estado de desprestigio en el que se encuentran en toda la región.

En América Latina la reflexión sobre la democracia fue muy significativa en los años de lucha contra los regímenes autoritarios y en los esfuerzos por construir en los años $\mathbf{8 0}$ democracias estables y equitativas. Después de una década de apatía teó-

4 Retomo, en parte textualmente, algunos planteamientos ya hechos en “Democracia participativa y liberalismo político". En: Hermenéutica jurídica. Homenaje al Maestro Darío Echandía. Bogotá: Universidad del Rosario, 1997, p. 241-252, reeditado como “Democracia y derecho. El debate entre Habermas y Rawls". En: Pensamiento jurídico, Revista de teoría del derecho y análisis jurídico, № 8, Bogotá: Universidad Nacional de Colombia, Facultad de Derecho, 1997, pp. 113-122.

5 Diario de la Asamblea Nacional Constituyente, 5 de feb. de 1991, p. 7.

6 Gaceta Constitucional, 7 de julio de 1991, p. 31. 
rica, los efectos de despolitización del neoliberalismo en manos de neófitos han hecho impostergable una renovada discusión sobre la participación política. Tres fenómenos confieren significado específico a este debate: la corrupción y sus derivados, como las 'narcodemocracias', el aumento acelerado de las desigualdades socioeconómicas y, en íntima relación con estos dos puntos, la violencia guerrillera, que parecía haber quedado sin piso tras la transición a la democracia y el fin de la guerra fría, y ahora gana nuevos argumentos en la pobreza y la discriminación, aleccionada por el abstencionismo y la ilegitimidad de democracias meramente formales, autoritarias y corruptas.

Quizá nadie mejor que los Zapatistas de México para ejemplificar lo que ocurre y al mismo tiempo motivar nuevos planteamientos y nuevas propuestas. En entrevista del Año Nuevo 1997 para El Espectador de Bogotá7, el "subcomandante Marcos" anunciaba: "Ahí vamos a estar dando lata, haciendo encuentros, convenciones, peleando o escribiendo, hasta que nos maten o nos den el mundo que estamos pidiendo... Un mundo donde quepan los zapatistas pero también los otros, quienes quieran que sean los otros... Este es un aporte del zapatismo que tiene que ver, más que con la supuesta claridad política de Marcos, con el aporte de las comunidades indígenas al movimiento: esta aparente locura que dice que no se trata de tomar el poder sino de algo 'más sencillo', que es cambiar el mundo, cambiar todas la relaciones políticas... Nuestro objetivo es poder realmente abrir los espacios de lucha para toda la sociedad... que la guerrilla combata pero también haga política, que reconozca la política y la lucha de ideas como un campo de batalla... No pretendemos tener la única palabra. Aceptamos que hay otras ideas y que el mañana va a ser construido con la participación de otros. Insis- timos en que la solución debe ser producto de las fuerzas sociales... Si fuera posible construir el camino de la paz a través de nuestros contactos directos con la sociedad civil y con los zapatistas civiles, la paz ya estaría firmada".

A la pregunta: ¿De qué prácticas guerrilleras toman distancia los zapatistas?, responde: "Primero, nosotros no nos volveríamos contra nosotros mismos. No justificaríamos ataques a la población civil, cualquiera que sea este fin... Cuando un ejército se dedica a pelear contra la población civil se convierte en un monstruo, en un enfermo que asesina por placer y no por necesidad, si es que hay alguna necesidad que justifique el asesinato de civiles. Si enfrentamos a un régimen criminal que basa todo su poder en las armas, no estaríamos dispuestos a construir otro régimen sobre el poder de nuestras armas, aunque sean de palo, como dicen que son las armas de los zapatistas".

Nos preguntamos por tanto si la democracia participativa puede ayudar a reconstruir una Colombia en la que quepamos todos. No se trata de invitar a los excluidos a integrarse a un país en cuya definición ellos no han participado. La inclusión de la otra Colombia en el proyecto de un renovado 'contrato social' presupone una discusión política amplia e 'incluyente's. Precisamente los procesos de paz deben proponerse inicialmente como invitación a participar en el diseño de un país en el que se incluya desde el principio a todos sin discriminación de ninguna especie: este es el sentido del pluralismo razonable. Sólo así se puede lograr el consenso entrecruzado sobre mínimos, de acuerdo con lo que una concepción discursiva del derecho promete y garantiza: que sólo se acepten como válidas aquellas normas en cuya constitución hayan podido participar todos los afectados.

Enero 5 de 1997, pp. 10 y 11 A.

8 Ver recientemente: HABERMAS, Jürgen. Die Einbeziehung des Anderen. Studien zur politischen Theorie. Suhrkamp, 1997; y Habermas, Jürgen, Die postnationale Konstellation. Politische Essays. Suhrkamp, Frankfurt, 1998. 
En su reciente obra Thick and Thin (Denso y tenue), M. Walzer logra desde un principio ponernos a marchar con la gente que a finales de 1989 en la insurrección en Praga portaba carteles, unos reclamando "verdad" y otros "justicia" 9 . Se trata de sentimientos morales, no sólo los negativos de P. F. Strawson ${ }^{10}$, sino los del entusiasmo que develan una intuición de que pertenecemos a esas marchas casi antes de pensarlo. Algo semejante a lo que frente a la revolución francesa hacía expresar a Kant en El conflicto de las facultades "un deseo de participación que frisa en el entusiasmo" ${ }^{\prime 11}$. Esto mismo lleva a Walzer a preguntarse más adelante: “ ¿qué haría la crítica cuando mire a su alrededor y vea gobiernos tiranos en otros países, en lugares lejanos, y gente marchando en la calle oponiéndose a sus legisladores, demandando no sólo 'verdad' y 'justicia' sino también 'democracia'?"12.

Una posición moral tenue, orientada hacia mínimos fundamentales, nos convertiría en participantes virtuales de dichas marchas. Como nosotros también quienes marchan tienen ciertamente su comprensión moral densa, basada en principios omnicomprensivos, que aunque pretenda ser "la correcta" para nosotros, no puede llegar a serlo para todos. "Un día -concluye Walzer- sin duda, ellos producirán su propia versión de la democracia, y entonces se encenderá la controversia acerca de si podría ser más o menos 'participativa', y quizá yo me sumaré a la controversia no como un crítico social, sino simplemente como un estudioso interesado, eventualmente como politólogo"13.

¿Pero qué nos permitiría hablar de más o menos "participación"? ¿Qué nos motivaría para reconstruir participativamente la política y su inmediato resultado, el derecho? Para el mismo Walzer, dado que el principio del consentimiento establece una ética procedimental, ésta describe cómo se llega legítimamente a ejercer el poder. "De hecho, lo que hace que el procedimiento proceda, lo que le da su fuerza legitimadora, es un cierto espíritu expresado en una serie de prácticas. El espíritu es el del compromiso activo, y las prácticas incluyen argumentar, organizar, reunirse en asambleas, demostrar, y demandar lo mismo que votar". Por ello se "caracteriza la democracia con una serie de esfuerzos explícitos para crear y sostener una ciudadanía activa"14. Esto hace que "la política democrática, inclusive en su forma ideal, sólo sea en parte argumentativa; también es asunto de organización, negociación, estrategia, demostraciones de fuerza y mucho más" ${ }^{15}$.

Lo anterior nos permite hablar de un principio ético de la democracia, el pluralismo democrático incluyente que da sentido al procedimentalismo, el cual no "funciona" si no es por el espíritu de participación ciudadana, que a la vez inspira unas prácticas. Por tanto lo determinante de la democracia es la actividad y el espíritu que la anima e inspira, no sólo el resultado de dicha actividad, que es precisamente el derecho, que con frecuencia puede ser deficiente ${ }^{16}$.

¿Puede la participación democrática reconstruir lo público de la política y lo justo del derecho, privatizado por los intereses de los poderosos, reducido con la pobreza a mero espacio físico de supervivencia, enrarecido por el abstencionismo, distorsionado por medios al servicio del capital,

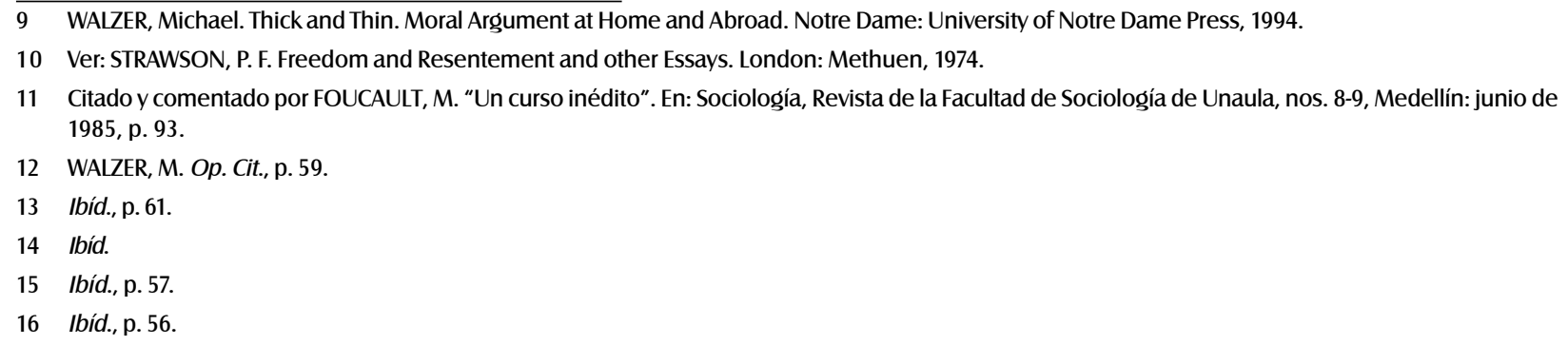


manipulado y cerrado por la corrupción y por la violencia? ¿Logra una radicalización de la democracia en la forma de democracia participativa solucionar 'desde la raíz' el problema de los derechos socioeconómicos, privando así de uno de sus argumentos a la violencia guerrillera? ¿Puede una sociedad comprometida realmente en procesos democráticos no sólo implantar la justicia como equidad sino también develar la corrupción y recobrar el sentido de legitimidad del Estado social de derecho? En otras palabras: si se considera que la violencia guerrillera todavía tiene un argumento político, éste podría ser el de que se excluye a una parte de la población de la participación política y se la priva de sus derechos socioeconómicos fundamentales. Además se alienta la esperanza de que a mayor participación de la ciudadanía más control político sobre las prácticas autoritarias y corruptas; esto puede significar a corto plazo la revitalización de los partidos políticos en el mejor sentido de su función con respecto al fortalecimiento del Estado social de derecho democrático. ¿Hasta qué punto se puede entonces ampliar el sentido de participación democrática, de suerte que con ello se pueda quitar el piso a las razones políticas de la violencia y se recuperen las fuentes de legitimidad del derecho que animen la lucha contra la corrupción y reorienten la administración al servicio de la comunidad?

Sin pretender reemplazar el trabajo necesario de los científicos políticos en este campo, pienso que -como lo han sugerido A. Wellmer ${ }^{17} y$ Th. McCarthy ${ }^{18}$-, el debate entre J. Rawls y J. Habermas $^{19}$, a partir de sus recientes obras, Liberalismo político y Facticidad y validez, permite destacar la necesidad de una democracia participativa para dar todo el sentido a la propuesta estructural del liberalismo político como fuente inequívoca del derecho moderno. Al desarrollar la complementariedad de las dos propuestas se evita la burocratización de un liberalismo político no animado por procesos de auténtica participación democrática, peligro inherente a la concepción rawlsiana del Estado liberal, a la vez que se protege de la anarquía a una participación no orientada hacia instituciones legítimas, escollo que tiene que superar la concepción habermasiana de política. La complementariedad significa llevar a síntesis lo mejor de la propuesta estructural de un Estado de derecho y de la propuesta política de la democracia participativa.

\section{El derecho entre la moral y la política}

Comencemos por rescatar el sentido del problema con la ayuda de la pregunta que lleva a J. Rawls a proponer el liberalismo político: “ ¿Cómo es posible que exista por tiempo prolongado una sociedad estable y justa de ciudadanos libres e iguales profundamente divididos por doctrinas razonables, aunque incompatibles, de índole religiosa, filosófica y moral? En otras palabras: ¿Cómo es posible que puedan convivir doctrinas omnicomprensivas profundamente opuestas aunque razonables y que todas ellas acepten la concepción política de un régimen constitucional?"20.

Como es bien sabido, para Rawls la solución se da sólo a partir de un pluralismo razonable, en el que las doctrinas omnicomprensivas se reconocen recíprocamente, pero deben ser neutralizadas políticamente para lograr un consenso entrecruzado sobre aquellos mínimos que fundan la justicia como equidad en el liberalismo político y no ya en algu-

\footnotetext{
17 WELLMER, Albrecht. «Bedingungen einer demokratischen Kultur. Zur Debatte zwischen Liberalen und Kommunitaristen». En: BRUMLIK, Micha y BRUNKHORST, Hauke (Hrsg.). Gemeinschaft und Gerechtigkeit. Frankfurt, a.M.: Fischer, 1993, pp. 173-196.

18 MCCARTHY, Thomas. "Kantian Constructivism and Reconstructivism: Rawls and Habermas in Dialogue". En: Ethics, № 105, 1994, pp. 44-63.

19 The Journal of Philosophy, Vol. XCII, No. 3, March, pp. 109-180 (v.e., Habermas Jürgen / Rawls, John. Debate sobre el liberalismo político. Barcelona, Paidos, 1998).

20 Rawls, John. Political Liberalism. New York: Columbia University Press, 1993, p. XVIII.
} 
no de los metarrelatos, de las morales densas, de las concepciones omnicomprensivas en las que se originan los procesos de búsqueda de consensos. Estos mínimos conformarían el núcleo de la Constitución que se daría una sociedad para buscar su ordenamiento con base en derecho. Todo esto sólo es posible si se distingue claramente entre filosofía moral y filosofía política ${ }^{21}$ y entre lo no público y las razones públicas que consolidan el núcleo fundamental de este renovado contrato social ${ }^{22}$. Gracias a esta distinción se constituye en su especificidad el sentido de lo político y en su línea del derecho. Pero también esta tajante distinción radicaliza la discontinuidad entre moral y política en el liberalismo, como lo señala R. Dworkin en su Ética privada e igualitarismo político ${ }^{23}$.

Dworkin ensaya, oponiéndose al último Rawls, el camino de la continuidad, mostrando "que la política liberal surge... cuando se activan plenamente aquellas convicciones éticas que son más globales y filosóficas. Desde este punto de vista, la ética y la política están interrelacionadas de tal forma que algunas de las cuestiones de mayor alcance acerca del carácter de la buena vida son también cuestiones políticas" ${ }^{24}$. Mientras para Rawls el punto de partida es una posición originaria con 'velo de ignorancia' para permitir un pluralismo razonable que garantice imparcialidad como base en el ejercicio constructivo de los principios de la justicia como equidad, "la estrategia de la continuidad, por el contrario, espera llegar a la neutralidad a su debido tiempo, en el curso del argumento, no al comienzo del mismo"25. Es el procedimiento político por sí mismo, el de la democracia participativa, el que
Ileva a la imparcialidad y objetividad que reclama la forma jurídica.

Lo que se busca en un liberalismo ético es precisamente superar la frialdad del liberalismo clásico y la frivolidad del actual, de suerte que como ámbito político para ejercicio de la democracia pueda volver a entusiasmar a la gente, puesto que en él se juegan ideales humanitarios y una concepción de vida buena, por la cual vale la pena luchar. Por ello, frente al pragmatismo del mero derecho positivo como garante de eficiencia y de 'impacto', propone Dworkin una ética del 'desafío', que inspire la participación ciudadana, para la cual vivir bien tiene una dimensión social, ya que: "no vivo tan bien si vivo en una comunidad en la que otros consideran que mis esfuerzos por llevar una buena vida son empeños que carecen de importancia. En realidad, resulta insultante para todo el mundo un sistema político y económico consagrado a la desigualdad, incluso para aquellos cuyos recursos se benefician de la injusticia"26.

De esta forma la igualdad, la libertad y la comunidad se van constituyendo, también jurídica e institucionalmente, fundidas una con otra en un ideal político global, alcanzable mediante luchas democráticas por el reconocimiento, base del pluralismo razonable, luchas en las que se articulan a la vez la autonomía privada de los ciudadanos, su libertad individual y su autonomía pública, como libertad política. Quiere decir que para proteger el sentido objetivo del derecho, antes que neutralizar su origen con imperativos morales de justicia formal, es necesario fomentar la participación y el

\footnotetext{
21 Ibíd., p.XV.

22 Ibíd., Lecture VI.

23 DWORKIN, Ronald. Ética privada e igualitarismo político. Barcelona: Paidos, 1993.

24 Ibíd., p. 65.

25 Ibíd., p. 66.

26 Ibíd., p. 179.
} 
compromiso político de todos los afectados por o interesados en su normatividad.

Todavía más radical es la crítica reciente de $M$. Sandel en su Democracy's Discontent ${ }^{27}$, a lo que él ha llamado la "república procedimental", una de cuyas formas de legitimación es el "liberalismo minimalista" de Rawls. "Dado que este liberalismo afirma la prioridad de procedimientos justos con respecto a los fines particulares, la vida pública que informa puede llamarse república procedimental"28. De ella se dice que "no puede contener las energías morales de la vida democrática activa. Crea un vacío que abre el camino a moralismos estrechos e intolerantes. Y no logra cultivar las cualidades de carácter que dotan a los ciudadanos para compartir el autocontrol". Tampoco "puede asegurar la libertad que promete porque no puede sostener la clase de comunidad política y de compromiso cívico que requiere la libertad"29.

Para comunitaristas, como Sandel, desterrar los argumentos morales del espacio público para buscar un consenso empobrece el discurso político y corroe los recursos morales de la sociedad civil. Al minimalismo liberal, que "define la libertad en oposición a la democracia, como garantía del individuo contra lo que la mayoría pudiera desear" ${ }^{\prime 30}$, hay que oponer una visión republicana de la libertad: "soy libre en cuanto soy miembro de una comunidad política que controla su propio destino y participo en las decisiones que gobiernan sus asuntos"31.

De hecho, el liberalismo político definido por Rawls restringe lo público al objeto del consenso entrecruzado: las esencias constitucionales y la justicia básica. Sólo en el "trasfondo cultural" de esta razón pública son tomadas en cuenta las otras razones de la sociedad civil ${ }^{32}$. Si también en esta misma dirección el constitucionalismo liberal se limita a defender, prescindiendo de la materialidad del derecho, sólo la prioridad de los derechos individuales, el ideal de neutralidad y una concepción puramente voluntarista de la libertad ${ }^{33}$, el sentido de lo público queda formalizado y empobrecido: como si los derechos humanos, la solidaridad y el sentido mismo de comunidad sólo llegaran hasta donde llega el contrato social. ¿En qué espacio se resuelve entonces la primacía de la vida pública de una nación sobre sus aspectos meramente constitucionales?

El aguijón del comunitarismo nos urge a resolver el dilema contemporáneo entre la concepción republicana y la liberal del Estado de derecho. Si continuidad y relación directa entre moral y política, entonces sí fortaleza motivacional e identidad cultural, pero también heteronomía de lo político, relativización del derecho, amenaza de los moralismos y de los particularismos nacionalistas. Si discontinuidad, es decir independencia del derecho y de la política con respecto a la moral, entonces sí universalismo y neutralidad, pero también frivolidad, funcionalización de la política, positivismo o realismo jurídico. Veamos si es posible solucionar el dilema acudiendo a una nueva distinción, ahora entre moral en el sentido kantiano y ética en el sentido aristotélico, de suerte que ya el derecho y la política no requieran como en Kant acudir a la

\footnotetext{
27 SANDEL, Michael J. Democracy's Discontent. America in Search of a Public Philosophy. Cambridge: Mass, The Belknap Press of Harvard University Press, 1996, pp. 17-24.

28 Ibíd., p. 4.

29 Ibíd., p. 24.

30 Ibíd., p. 28.

31 Ibíd., p. 26. El ideal de Sandel parece seguir orientado por aquel vínculo entre libertad y democracia que se encuentra en las descripciones del sistema municipal de Nueva Inglaterra, hechas por Tocqueville: "Las instituciones municipales son a la libertad lo que las escuelas primarias a la ciencia; ellas son las que la ponen al alcance del pueblo; le hacen gustar de su uso pacífico y lo habitúan a servirse de ella. Sin instituciones municipales, una nación puede darse un gobierno libre, pero carecerá del espíritu de la libertad" (La democracia en América, Tomo I, Cap. V, Madrid: Alianza, 1981, p. 59).

32 Rawls, John. “La idea de una razón pública”. En: Isegoría, No. 9, Madrid, abril de 1994, pp. 5-40.

33 Ver: Sandel, M. Op.Cit., p. 28.
} 
moral para ganar legitimidad, sino que se constituyan en el seno mismo de la participación ciudadana, en la cual se articula la soberanía popular. Se lograría así una concepción procedimentalista del derecho: la reconstrucción de su génesis a partir del poder comunicativo de la sociedad civil lo reactivaría como instrumento de solución de conflictos, de regulación y organización social y, en una palabra, de participación política en un horizonte definido, en el más extenso y estricto sentido de la palabra, como Estado democrático de derecho. Si en el paradigma comunicativo se permitiera todavía la figura de la deducción trascendental, podríamos decir que en lugar de deducir el derecho de la moral, como lo hace Kant, estaríamos deduciendo la democracia del derecho, de forma que la facticidad de la democracia se reconozca como condición de posibilidad de la validez del derecho, es decir que éste sea efectivamente derecho legítimo vigente, reconocido como tal por los ciudadanos.

\section{Democratizar la democracia para devolver el derecho a los ciudadanos}

La concepción procedimentalista del derecho busca superar la unilateralidad y ceguera complementaria del paradigma liberal del derecho (protección de la autonomía privada pero olvido de la equidad social) y del paradigma jurídico ligado al Estado social (fomento de la justicia distributiva pero con paternalismo), apostando al poder comunicativo de Ios ciudadanos: “Un orden jurídico es legítimo en la medida en que asegura la cooriginaria autonomía privada y autonomía ciudadana de sus destinatarios; pero al propio tiempo debe su legitimidad a las formas de comunicación, en las cuales solamente puede esa autonomía expresarse y acreditarse" ${ }^{\prime 34}$.
La referencia a las relaciones de comunicación de las que surge el poder político y en las que se genera el derecho legítimo, nos obliga a explicitar el sentido complejo de la acción comunicativa en el mundo de la vida. Las estructuras comunicativas de la sociedad civil permiten vincular el pluralismo razonable y el consenso, esos dos momentos que interrumpe el liberalismo, como etapas necesarias de un proceso de entendimiento entre los ciudadanos, de participación política y de génesis democrática del derecho. En efecto, en el mundo de la vida como horizonte ilimitado de contextos, nivel hermenéutico de la comunicación, donde comprender otras culturas no me obliga a identificarme con ellas, se tejen las redes de la sociedad civil en el más originario sentido de lo público. El compromiso valorativo y los sentimientos morales que se expresan en este nivel originario de la comunicación, no sólo no son obstáculo epistemológico (como parece temerlo el liberalismo) para reconocer a otros y para dilucidar aquello en lo que pudiéramos coincidir con ellos. La sensibilidad social que valora, antes que obstáculo, es fuerza motivacional necesaria para la participación política (como lo reclama acertadamente el comunitarismo). En este reino de la diferencia, donde en un buen sentido 'todo da lo mismo', 'todo vale', desde el pluralismo razonable es necesario el reconocimiento del otro como interlocutor válido, es decir, como quien en igualdad de derechos y desde perspectivas diversas lucha, negocia, argumenta y, en una palabra, participa en favor de concepciones del bien y de la vida que enriquezcan la reciprocidad ${ }^{35}$, la solidaridad ${ }^{36}$ y la cooperación social. El punto de partida para la constitución del Estado de derecho democrático es sin lugar a dudas una concepción de sociedad civil en la que quepan todos.

\footnotetext{
34 Habermas, J. Facticidad y validez, Op. Cit., pp. 491-492.

35 Rawls, J. Political Liberalism, Op. Cit., p. 16.

36 HABERMAS, Jürgen. Faktizität und Geltung. Beiträge zur Diskurstheorie des Rechts und des demokratischen Rechtsstaats. Frankfurt, a.M.: Suhrkamp, 1992, p. 163.
} 
Un segundo momento de la comunicación, provocado por la multiplicidad de puntos de vista del primero, es el que puede conducir a acuerdos con base en las mejores razones y motivos. Aquí se despliega en toda su riqueza la política deliberativa: ésta consigue en el mundo de la vida, que también es fuente inagotable de recursos para validar lo 'correcto', el que tanto los consensos como los disensos no sólo tengan la fuerza de convicción propia del discurso, sino en el mismo acto el poder ético motivacional propio de la voluntad comprometida con el acuerdo ciudadano no coactivo. La democracia participativa es a la vez vida de la sociedad civil, al reconstruir la solidaridad, y procedimiento para llegar libremente a consensos y disensos de relevancia política, jurídica y constitucional. La democracia participativa se convierte pues en génesis lógica del derecho con su doble función: solucionar conflictos entre personas y grupos y de éstas y éstos con el Estado (concepción liberal del derecho), y al mismo tiempo orientar concertadamente la cooperación ciudadana hacia fines colectivos en busca del bien común (concepción republicana).

Se trata pues de una estrategia de la continuidad, semejante a la de Dworkin. La teoría discursiva de la política y del derecho abre desde un principio la polis en el más estricto sentido de lo público a la participación democrática de todos los ciudadanos, en búsqueda tanto de comprensión de la complejidad de la sociedad civil, como de acuerdos mínimos que constituyan el Estado social de derecho ${ }^{37}$. Para ello es necesario emancipar de la moral al derecho moderno, para restablecer todo su sentido y legitimidad con base en la política; y esto depende del grado de participación que asegure la democracia de acuerdo con el principio general de toda normatividad, no sólo moral, sino también jurídica: "sólo son válidas aquellas normas de acción con las que pudieran estar de acuerdo como participantes en discursos racionales todos aquellos que de alguna forma pudieran ser afectados por dichas normas" ${ }^{\prime \prime 3}$.

Con esta especie de "sustitución" de la moral por la participación democrática en el ámbito de lo ético-político, se logra reconstruir la complementariedad entre posiciones extremas que parecerían irreconciliables ${ }^{39}$ : "las libertades de los antiguos" para el ejercicio de los derechos políticos de participación se consolidan como derechos humanos, en la forma renovada de "las libertades de los modernos", gracias al reconocimiento mutuo de ciudadanos libres e iguales en procura de una sociedad justa con instituciones democráticas. $\mathrm{O}$ lo que es lo mismo: Ios derechos humanos del liberalismo sólo adquieren validez y relevancia en su ejercicio político público en la sociedad civil, ámbito de la soberanía popular. Esto permite articular la dialéctica entre "autonomía pública", propia de la participación política, y "autonomía privada", origen de las libertades individuales. Al reconciliarse en dicha dialéctica la "soberanía popular" y los "derechos civiles" de las personas, van alcanzando en la historia las luchas por los derechos humanos su cometido y se van consolidando constitucionalmente con base en movimientos sociales que abren el espacio público a la participación ciudadana de todos los asociados. En este ámbito también los derechos antes que bienes son recursos y competencias, como lo son los derechos socioeconómicos. Además, desde esta concepción participativa de los derechos, el multiculturalismo deja de ser un problema para convertirse en fuente de recursos cognitivos y motivacionales que animan la lucha

37 Retomo aquí algunos planteamiento de mi trabajo: «Etica discursiva, derecho y democracia». En: Análisis político. No. 20, Bogotá: Universidad Nacional de Colombia, septiembre a diciembre de 1993, pp. 5-19.

38 Habermas, J. Faktizität und Geltung, Op. Cit., p. 138.

39 Ver además del citado Journal of Philosophy: HABERMAS, Jürgen. “Postscript (1994)”. En: Between Facts and Norms. Cambridge: MIT Press, 1996 (traducción al inglés de su Faktizität und Geltung). 
democrática. Se rompe entonces la discontinuidad entre ideales de vida, propios del paradigma comunitarista, y procedimientos políticos conducentes a determinados acuerdos con fuerza jurídica vinculante: son ciudadanos de carne $y$ hueso, con sus necesidades de toda índole, con sus diversos dioses y demonios, los que llegan gracias a su actividad pública a posibles consensos sobre mínimos, que pueden adquirir forma jurídica.

Pero sobre todo la concepción procedimentalista del derecho con base en un sentido radical de democracia permite articular políticamente la exigencia de democracia directa de la "tradición republicana" con la de sólo representación del "liberalismo". El "poder comunicativo" que se genera éticopolíticamente en la sociedad civil, cuya caja de resonancia es la opinión pública, dinamiza la participación política, orientada por la necesidad de llegar a acuerdos que permitan solucionar los conflictos y buscar programas de cooperación en los asuntos relevantes para el bien común; la constitución y el derecho garantizan las soluciones de conflictos como lo sostiene el liberalismo político y convocan para las tareas comunes como lo proclama la tradición republicana.

Esto explica por qué para una democracia participativa que confiera legitimidad al Estado de derecho, es absolutamente indispensable una sociedad civil compleja y multicultural en íntima relación con un sentido vigoroso y crítico de lo público, como lo destaca expresamente Habermas en Facticidad y validez (Capítulo VIII). En ese contexto sugiere formas institucionales y no institucionales de hacer política y de producir derecho, todas ellas articuladas como 'poder comunicativo' en procesos de participación: elementos plebiscitarios en la Constitución, consultas populares, democratización de los partidos, oposición extraparlamentaria, etc.; al mismo tiempo cierta constitucionalización de los medios, para que, independientes de elites políticas o de otra clase, aseguren la libertad comunicativa de los ciudadanos para la formación de la opinión pública. "En un paradigma procedimental del derecho se presenta la opinión pública política no sólo como antesala del complejo parlamentario, sino como la periferia que impulsa y encierra el centro mismo de lo político: el público influye con un presupuesto de razones normativas, sin pretensión de conquista, en todas las órbitas del sistema político" ${ }^{\prime 4}$.

Un caso paradigmático, sobre todo desde la perspectiva en que introdujimos el sentido de la democracia participativa de la Constitución Colombiana, es el de la desobediencia civil ${ }^{41}$ : se trata de actos de violación de lo establecido (protesta ciudadana, movimientos sociales, toma de tierras, etc.) para exigir de los que gobiernan que revisen la legislación y apelar al sentido de justicia del público. En estos casos se manifiesta la conciencia de la sociedad de su poder para presionar al sistema político de suerte que solucione los conflictos de acuerdo con principios constitucionales y morales. Se tiene por tanto una concepción dinámica de la constitución como un proyecto nunca terminado y de la historicidad del derecho: una y otro son dispositivos de aprendizaje de solución concertada de aquellos conflictos que nos hemos acostumbrado inveteradamente a solucionar violentamente $y$ de cooperación social, para abordar aquellas tareas que no pueden realizarse exitosamente sin la colaboración social. Es por tanto de competencia de la sociedad civil poder evaluar y reformar una Carta, que antes que todo es carta de navegación para vincularse a aquellos proyectos y programas que fomenten la concepción del bien de los ciudadanos.

Si se da todo el peso a la democracia participativa, no sólo para solucionar el problema de las diferencias culturales, sino sobre todo el de las desigual-

\footnotetext{
40 Habermas, J. Faktizität und Geltung..., Op. Cit., p. 533.

41 Ibíd., pp. 462-464.
} 
dades sociales y económicas, hay que desarrollar el sentido deliberativo de política, el cual implica una pedagogía de la comunicación y de la convicción, una comprensión fuerte de lo público y una concepción lo suficientemente compleja de la sociedad civil. Pero entonces es necesario que las formas no convencionales de participación no sean demonizadas, como ocurre no pocas veces, cuando el sentido de la democracia participativa no está lo suficientemente desarrollado en toda su complejidad. El derecho de asociarse y manifestarse públicamente está a veces sujeto a los excesos y suspicacias de las autoridades.

Aquí cabe también preguntar, para concluir, por los límites entre la desobediencia civil y las diversas formas de violencia, incluyendo la de las guerrillas. ¿En qué momento la participación pierde su sentido democrático para convertirse en puro instrumento? La desobediencia civil y la insurrección pueden llegar a justificarse no sólo por su destino final para implantar pedagogías y soluciones democráticas, sino por su compromiso con el "poder comunicativo" como única fuente de legitimidad de todo poder político, jurídico o estatal. Puede ser necesario violentar su restauración, pero sin renunciar a la participación democrática. En este sentido, cuando se habla de diálogos de paz, no es sólo porque con ellos se llegue a acuerdos sobre algo, es decir a una nueva Constitución, sino sobre todo porque quienes dialogan para restablecer la convivencia se comprometen con la sustancia de la democracia y la posibilidad del derecho: lo público y la comunicación.

El conservar un sentido comunicativo fuerte de lo público como paradigma de la democracia participativa aun en medio de las armas tiene su importancia en ambas direcciones: señala que el autoritarismo y la corrupción cierran el espacio de la participación de la misma forma que la violencia, al cancelar todo espacio para la imaginación política y toda posibilidad de recuperar credibilidad para la democracia. No sólo la violencia cierra el espacio del diálogo y del entendimiento, sino que el mismo rechazo al diálogo, aun en medio de las armas, cancela toda posibilidad de construir esa Colombia en la que podamos encontrarnos todos, respetando nuestras diferencias de toda índole. De la construcción de esta Colombia son responsables no sólo los así llamados poderes establecidos, sino quienes dicen tenerlos que combatir para buscar el cambio. Unos y otros no pueden pensar sólo en sí mismos, puesto que es la sociedad civil la que les exige dialogar con ella misma acerca de ese país en el que quepamos todos. Evadir dicha responsabilidad priva a unos y otros de legitimidad ante todos los que tienen derecho como compatriotas a autoincluirse en esa nueva Colombia, que debe ser reconstruida sobre las bases del Estado social de derecho democrático.

Es así como el diálogo, el poder comunicativo, la negociación y la concertación son en sí mismos normativos. Su vocación política, participativa y procedimental da sentido a la democracia moderna y legitima el derecho como aquello que nos inventamos los humanos, al alejarse los dioses, desvanecerse los metarrelatos y desacralizarse las ideologías, como algo necesario y útil para solucionar los conflictos de manera no violenta. Provocar soluciones violentas a conflictos ya en sí violentos, anteponiendo razones de prestigio, de protagonismo político o de vanguardismo revolucionario, que cancelen definitivamente las posibilidades de entendimiento y de participación ciudadana, no sólo es una torpeza histórica, como nos lo enseña un pasado reciente, sino una irresponsabilidad al perpetuar así la violencia institucionalizada que se pretende evitar. 